\title{
Sulforaphane induced cell cycle arrest in the G2/M phase via the blockade of cyclin B1/CDC2 in human ovarian cancer cells
}

\author{
Chi-Chang Chang ${ }^{1,2,5^{*}}$, Chao-Ming Hung ${ }^{3}$, Yun-Ru Yang ${ }^{4,6}$, Mon-Juan Lee ${ }^{4}$ and Yi-Chiang Hsu 5,6*
}

\begin{abstract}
Background: Malignant tumors are the single most common cause of death and the mortality rate of ovarian cancer is the highest among gynecological disorders. The excision of benign tumors is generally followed by complete recovery; however, the activity of cancer cells often results in rapid proliferation even after the tumor has been excised completely. Thus, clinical treatment must be supplemented by auxiliary chemotherapy or radiotherapy. Sulforaphane (SFN) is an extract from the mustard family recognized for its anti-oxidation abilities, phase 2 enzyme induction, and anti-tumor activity.
\end{abstract}

Methods: This study investigated the cell cycle arrest in G2/M by SFN and the expression of cyclin B1, Cdc2, and the cyclin B1/CDC2 complex in PA-1 cells using western blotting and co-IP western blotting.

Results: This study investigated the anticancer effects of dietary isothiocyanate SFN on ovarian cancer, using cancer cells line PA-1. SFN-treated cells accumulated in metaphase by CDC2 down-regulation and dissociation of the cyclin B1/CDC2 complex.

Conclusion: Our findings suggest that, in addition to the known effects on cancer prevention, SFN may also provide antitumor activity in established ovarian cancer.

Keywords: Ovarian cancer, Sulforaphane (SFN), Cell cycle, Cyclin B1/CDC2

\section{Background}

Isothiocyanates (ITCs) are naturally occurring components of vegetables that have demonstrated biological activity against carcinogenesis as well as chemopreventive properties [1]. It has been suggested that in conjunction with chemotherapy, ITCs may enhance drug sensitivity [2]. Sulforaphane (SFN), a potent cancer preventive agent, is a dietary isothiocyanate found as a precursor glucosinolate in cruciferous vegetables such as Brussels sprouts, cauliflower and broccoli [3]. Interest in this agent has grown in recent years due to its putative beneficial pharmacological effects as an antioxidant [4], anti-inflammatory [5] and antitumor agent [6]. SFN is also a potent scavenger of reactive oxygen species (ROS), including superoxide anions

\footnotetext{
*Correspondence: ed101779@edah.org.tw; jenway@mail.cjcu.edu.tw 'Department of Obstetrics \& Gynecology, Tainan Sin-Lau Hospital, Tainan, Taiwan ${ }^{5}$ Graduate Institute of Medical Science, College of Health Sciences, Chang Jung Christian University, Tainan, Taiwan

Full list of author information is available at the end of the article
}

and hydroxyl radicals [7]. Many studies have indicated an inverse correlation between the consumption of cruciferous vegetables and a decrease in the incidence of various tumors, including those of the prostate [8], cervical [9], colorectal [10], and lung [11]. In addition to inhibiting cell proliferation and increasing apoptosis [10], other mechanisms have also been proposed to explain the anti-carcinogenic effects of SFN. These include anti-inflammatory and antioxidative activities, the induction of phase 2 detoxification enzymes, the inhibition of cyclooxygenase 2 (COX-2) [12], and the effect on protein kinases [13].

This study investigated the influence of SFN on ovarian cancer cell lines (PA-1) with regard to the antiproliferation of PA-1 cells and induced cell cycle arrest in the G2/M phase. These results may provide support for the chemoprevention of ovarian cancer. 


\section{Methods}

\section{Materials}

Sulforaphane [1-isothiocyanato-(4R,S)-(methylsulfinyl) butane], DMSO (dimethyl sulfoxide) and MTT [3-(4,5dimethylthiazol-2-yl)-2,5-diphenyltetrazolium bromide], were obtained from Sigma (St Louis, MO). All other reagents and compounds were analytical grade.

\section{Cell culture}

PA-1 cells were purchased from the Food Industry Research and Development Institute (Hsinchu, Taiwan). The cells were maintained in flasks containing MEM supplemented with $10 \%(\mathrm{v} / \mathrm{v})$ FBS and cultured in an incubator at $37^{\circ} \mathrm{C}$ with an atmosphere containing $5 \% \mathrm{CO}_{2}$.

\section{Cell proliferation assay}

Cells were seeded into 96-well culture plates at 10,000 cells/well and treated with SFN. One to three days $(0 \mu \mathrm{M}$
SFN was the control group.) MTT dye $(1 \mathrm{mg} / \mathrm{ml})$ was added to each well 4 hours following treatment. The reaction was stopped by the addition of DMSO, and $\mathrm{OD}_{540}$ was measured using a multi-well plate reader (Powerwave XS, Biotek). In the absence of cells, the background absorbance of the medium was subtracted. Results were expressed as a percentage of the control, which was considered to be $100 \%$. Each assay was performed in triplicate and the results were expressed as the mean (+/-SEM).

\section{Measurement of apoptosis}

PA-1 cells were first seeded in 6-well plates (Orange Scientific, E.U.). Following treatment with SFN for four hours, the supernatant was discarded and cells were harvested and re-centrifuged. Cells were subsequently resuspended/incubated in $1 \mathrm{X}$ annexin-binding buffer (5 $\mu \mathrm{L}$ of annexin V-FITC [BD Pharmingen, BD, USA] and $1 \mu \mathrm{L}$ of $100 \mu \mathrm{g} / \mathrm{mL}$ PI working solution) for 15 minutes.

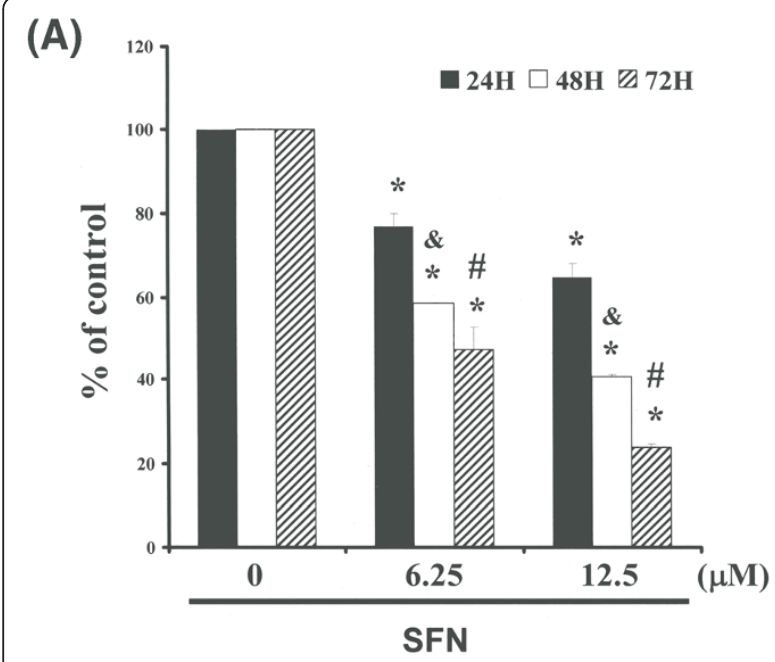

(C)

(B)
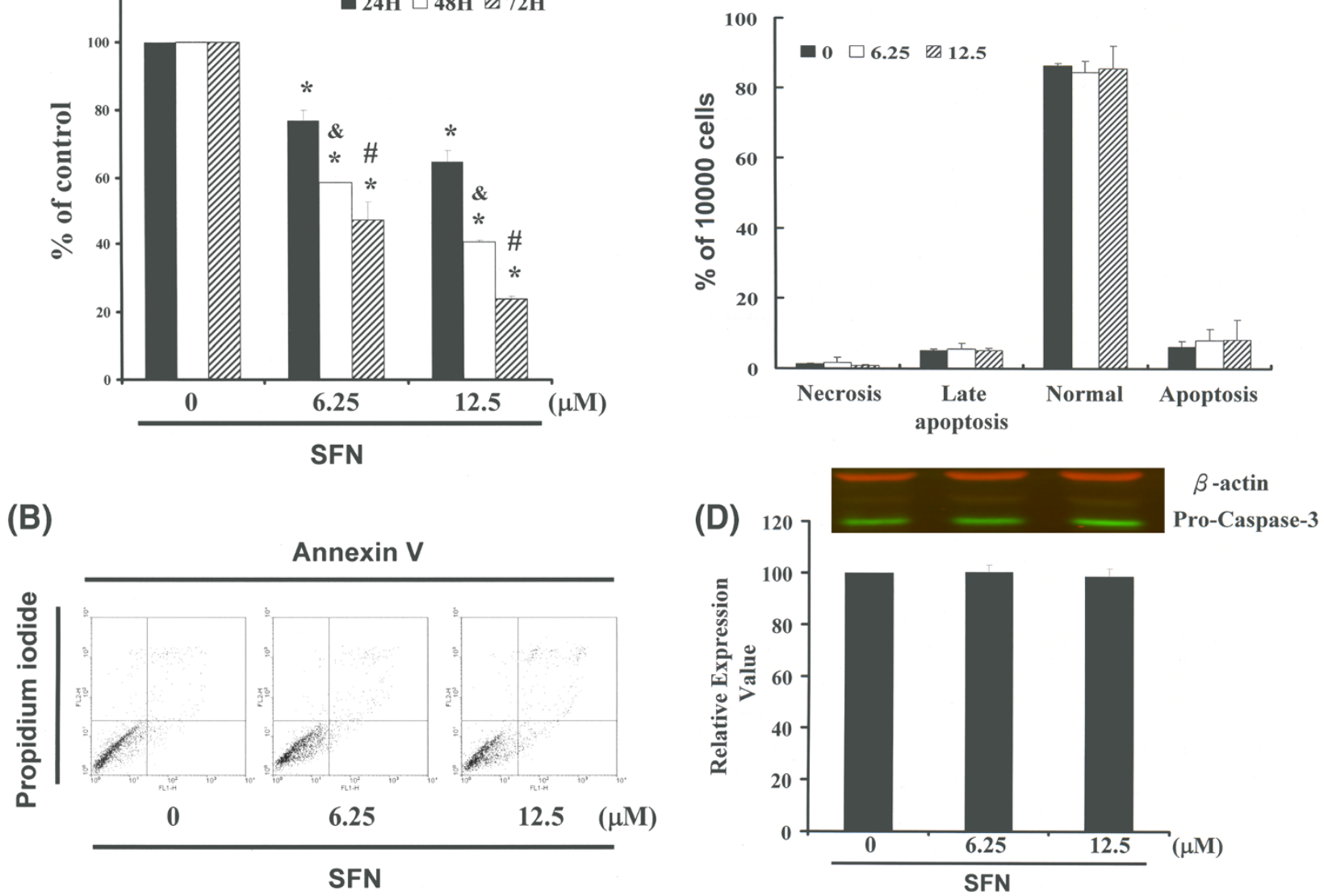

Figure 1 SFN mediates the survival of PA-1 cells, and thus inhibits proliferation: (A) In vitro study was initiated by treating each of the PA-1 cells with increasing doses of SFN for $\mathbf{2 4}$ to $\mathbf{7 2}$ hours. The survival of these SFN-treated cancer cells was then measured using the MTT method; (B) Influence of SFN on apoptosis in PA-1 cells; (C) Total apoptosis in PA-1 cells after $4 \mathrm{~h}$ of incubation with SFN; (D) Caspase-3 activation in PA-1 cells following SFN treatment. After being treated with SFN, cells underwent western blot analysis and band intensities (pro-caspase 3) were quantified using an Li-COR near infrared imaging system. Statistical analysis was performed using a t-test; the symbols *, \& and \# in each group of bars indicate that the differences resulting from treatment with SFN are statistically significant at $P<0.05$. 

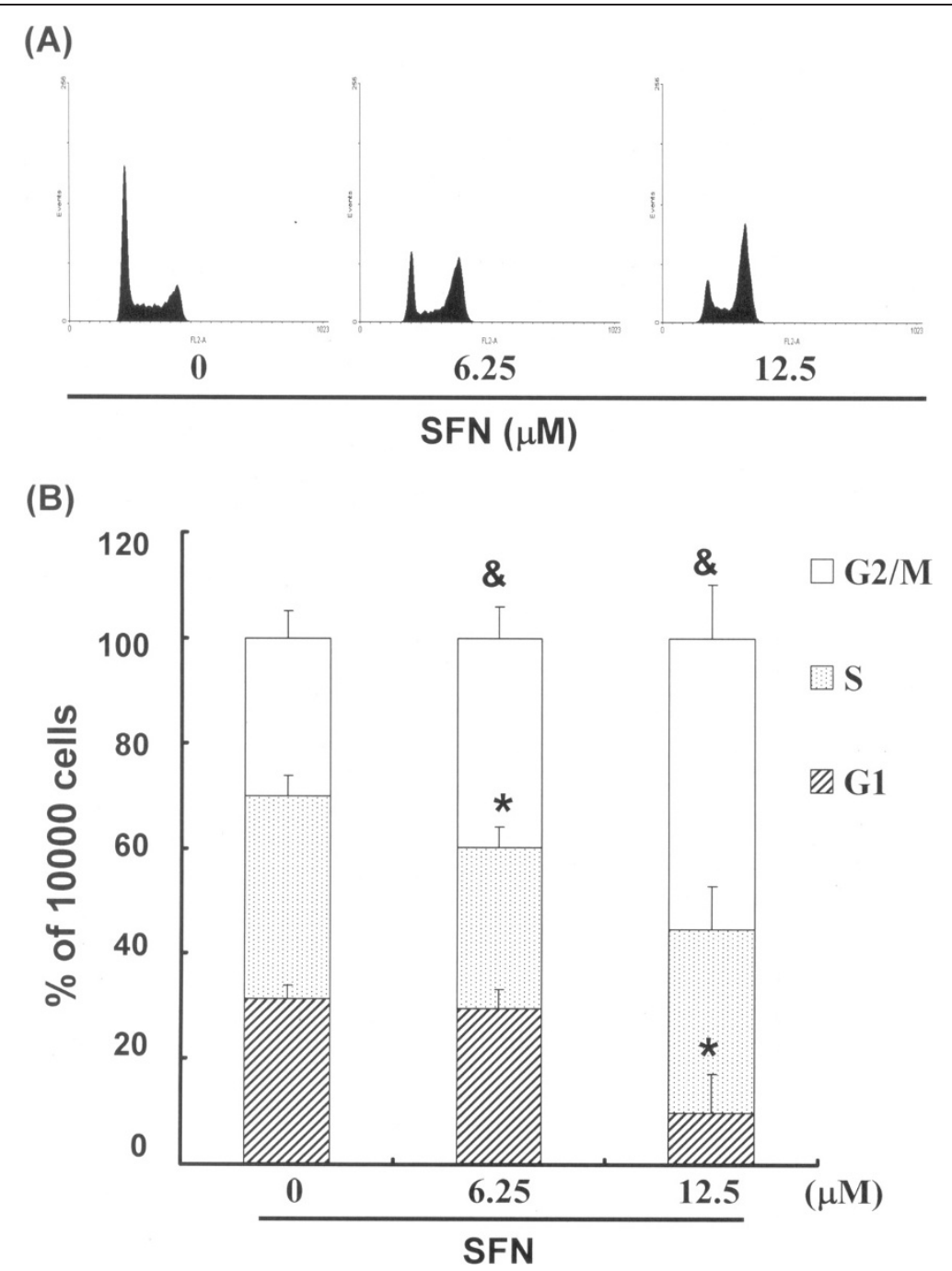

Figure 2 Influence of SFN on cell cycle progression/distribution in PA-1 cells: (A) Cell cycle analysis of PA-1 cells after being cultured with SFN for $24 \mathrm{~h}$; (B) SFN induced an increase in the number of $G_{2} / M$ phase cells (\%). The symbols * and \& in each group of bars indicates that the differences resulting from treatment with SFN is statistically significant at $P<0.05$.

Following incubation, the stained cells were analyzed using flow cytometry (FACSCalibur, BD, USA). Data was analyzed using WinMDI 2.8 free software (BD, USA).

\section{Cell cycle analysis}

Cell cycle analysis was performed using fluorescent nucleic acid dye and propidium iodide (PI) to identify the proportion of cells in each of the three stages of interphase. Cells were treated with SFN for 24 hours, and subsequently harvested and fixed in $1 \mathrm{ml}$ of cold $70 \%$ ethanol for at least eight hours at $-20^{\circ} \mathrm{C}$. DNA was stained in PI/RNaseA solution and the DNA content was detected using flow cytometry. Data was analyzed using WinMDI 2.8 free software (BD, USA).

\section{Western blot assay}

A total of $30-50 \mu \mathrm{g}$ of proteins were separated by $10 \%$ SDSPAGE and transferred to PVDF membranes (Millipore, USA). The membranes were blocked with blocking buffer (Odyddey, USA) overnight and subsequently incubated with anti- $\beta$-actin (Sigma-Aldrich, St. Louis, MO, USA), anti-CDC2, anti-caspase 3, and anti-cyclin B1 (Santa Cruz BioTechnology, USA) antibodies for $1.5 \sim 2$ hours. The blots were then washed and incubated with a second antibody (IRDye Li-COR, USA) at a dilution of $1 / 20,000$ for 30 minutes. Finally, the antigen was visualized using a near infrared imaging system (Odyssey LI-COR, USA) and data was analyzed using Odyssey 2.1 software. 


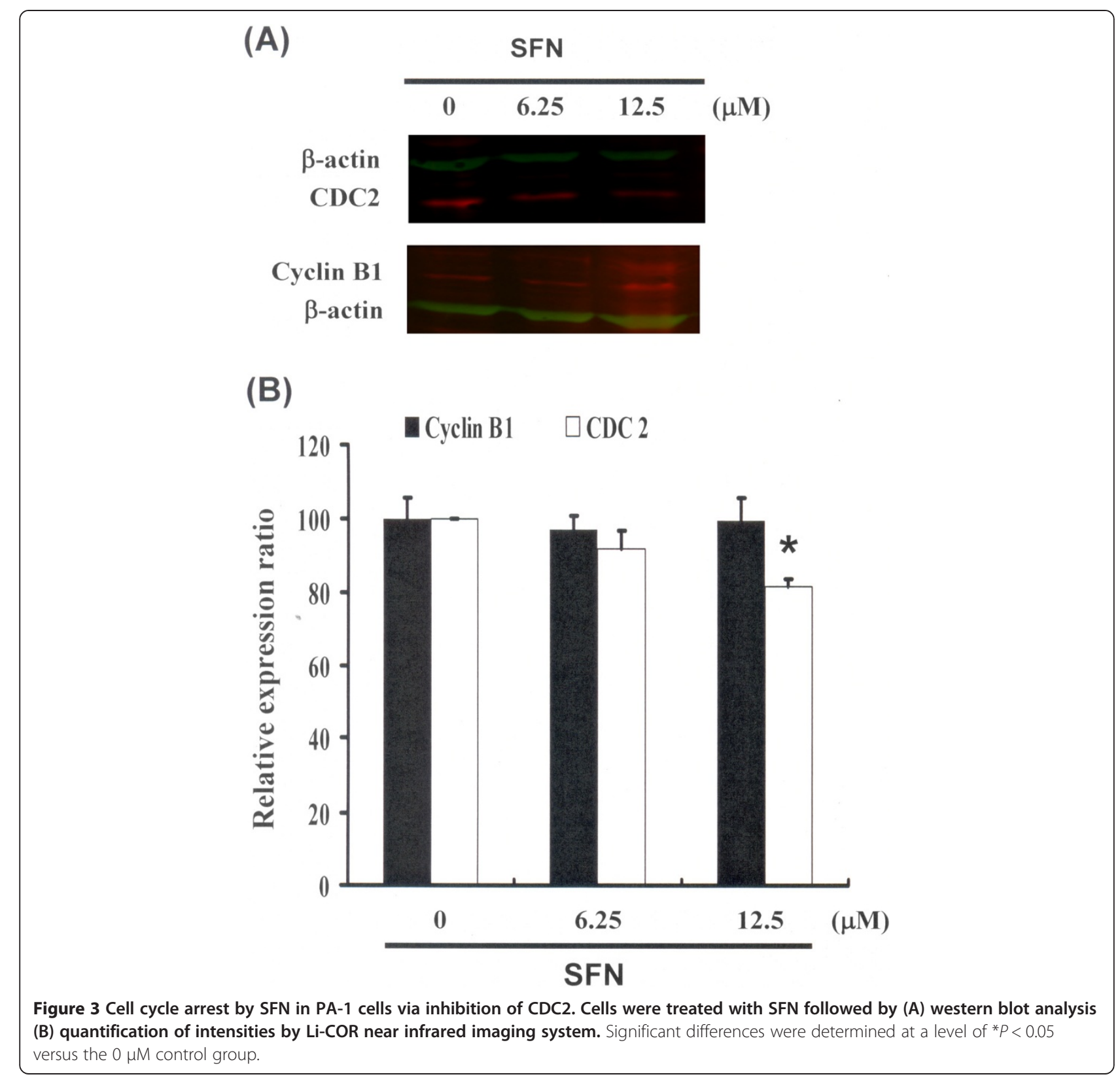

\section{Co-immunoprecipitation (Co-IP)}

Co-IP is an effective means of quantifying protein-protein interaction in cells. Briefly, $500 \mu \mathrm{g}$ of cellular proteins were labeled using anti-cyclin B1 (Santa Cruz BioTechnology, USA) following overnight incubation at room temperature. The protein-antibody immunoprecipitates were collected by protein A/G plus-agarose (Santa Cruz BioTechnology, USA). Following the final wash, the samples were boiled and centrifuged to pellet the agarose beads. Western blot analysis of the CDC2 protein in the supernatant was then conducted. Antigens were visualized using a near infrared imaging system (Odyssey LI-COR, USA) and data was analyzed using Odyssey 2.1 software.

\section{Statistical analysis}

All data was reported as the mean $( \pm$ SEM) of at least three separate experiments. A $t$-test or one-way ANOVA with post-hoc test was employed for statistical analysis, with significant differences determined as $P<0.05$.

\section{Results}

SFN inhibits proliferation of PA-1 cells

We hypothesized that SFN could mediate the survival of PA-1 cells and thus inhibit their growth. To explore the anti-tumor activity of SFN against PA-1 cells, an in vitro cell viability study was conducted in which 

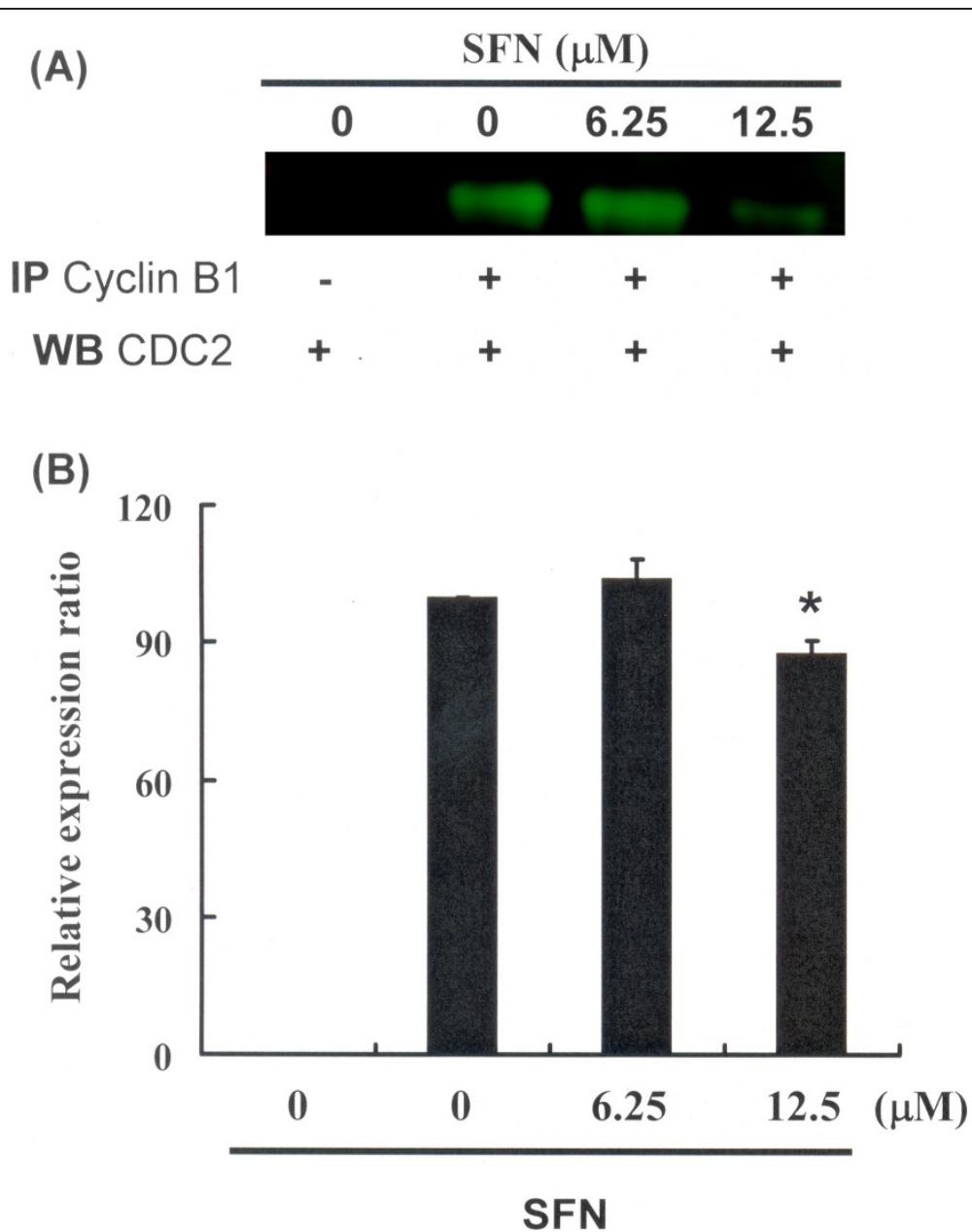

Figure 4 Mitosis delay by SFN in PA-1 cells via inhibition of Cdc2-cyclin B1 complex dissociation: Cells were treated with SFN followed by (A) Co-IP and western blot analysis, and (B) quantification of intensities by Li-COR near infrared imaging system. Significant differences were determined at a level of ${ }^{*} P<0.05$ versus the $0 \mu \mathrm{M}$ control group.

each sample of the PA-1 cells was treated with increasing doses of SFN $(0,6.25$, and $12.5 \mu \mathrm{M})$ for 24 to 72 hours. The results in (Figure 1A) indicate that the survival and proliferation of PA-1 cells were decreased by treatment with SFN in a dose-dependent (The 24 hours' $\mathrm{IC}_{50}$ of simvastatin in the PA-1 cancer cells was determined to be $17.083 \mu \mathrm{M} ; \mathrm{y}=-2.8213 \mathrm{x}+$ 98.199, $\left.\mathrm{R}^{2}=0.9697\right)($ " $<<0.05$ vs SFN $0 \mu \mathrm{M}$ group) and time-course manner ( $\& \mathrm{p}<0.05$ vs 24 hour treatment, \# $\mathrm{p}<0.05$ vs 48 hour treatment).

\section{SFN repressed the cell viability of PA-1 cells without apoptosis induction}

A study on apoptosis was performed to further elucidate anti-cancer mechanisms of SFN in PA-1 cells. After treating the cells with various doses of SFN, the percentage of apoptotic cells was assessed using Annexin VFITC and propidium iodide staining, followed by flow cytometric analysis (Figure 1B). A dot-plot of Annexin
V-FITC fluorescence versus PI fluorescence also indicated a non-significant increase in the percentage of apoptotic cells treated with SFN. At SFN concentrations of 6.25 to $12.5 \mu \mathrm{M}$, no significant increase was observed in the percentage of cells undergoing necrosis and apoptosis (Figure 1C) or caspase 3 activation (Figure 1D). The results summarized in Figure 1 indicate that SFN may mediate the survival of PA-1 cells and thus inhibit their proliferation without apoptosis induction.

\section{SFN treatment induced the accumulation of $G_{2} / M$ phase in PA-1 cells}

The cell-cycle distribution of SFN-treated PA-1 cells was analyzed using flow cytometry. Prior to processing and analysis, cells were exposed to SFN for a total of 24 hours. As shown in Figure 2A, the cells exposed to SFN showed an increase in the number of cells in the $\mathrm{G}_{2} / \mathrm{M}$ phase ( $\& \mathrm{p}<0.05$ vs SFN $\left.0 \mu \mathrm{M}\right)$, compared with the number of untreated cells. This could imply that the 
PA-1 cells had undergone cell cycle arrest. We also found that treatment with SFN simultaneously reduced the number of cells in the $\mathrm{G}_{1}$ phase (" $\mathrm{p}<0.05$ vs SFN $\left.0 \mu \mathrm{M}\right)$ (Figure 2B).

\section{Cell cycle arrest by SFN in PA-1 cells via CDC2 down regulation and dissociation of the cyclin $\mathrm{B} 1 / \mathrm{CDC} 2$ complex}

Figure 3 illustrates the immunoblotting of cellular proteins from PA-1 cells treated with SFN, revealing a decrease in CDC2 following incubation with SFN (Figure 3A). Cyclin $\mathrm{B} 1$ and $\mathrm{CDC} 2$ protein expression was quantified by measuring relative intensities. We found that $\mathrm{CDC} 2$ levels were significantly lower in cells incubated with SFN concentrations of $12.5 \mu \mathrm{M}$ (Figure 3B). Moreover, the activity of the cyclin $\mathrm{B} 1 / \mathrm{CDC} 2$ complex (important for G2-M transition during the cell cycle) was determined by Co-IP (Figure 4A) and quantified by measuring relative band intensities. We found that cyclin B1/CDC2 complex activity was significantly suppressed in cells incubated with an SFN concentration of $12.5 \mu \mathrm{M}$ (Figure 4B).

These results indicate an increase of the cell population in $G_{2} / M$ phase via a down regulation of $C D C 2$ and dissociation of the cyclin $\mathrm{B} 1 / \mathrm{CDC} 2$ complex following incubation with SFN in PA-1 cells.

\section{Discussion}

The results collected in this study using cell lines of human ovarian cancer provide experimental evidence indicating that SFN may induce irreversible cell cycle arrest during the G2/M phase. These dietary constituents demonstrate chemopreventive and chemotherapeutic potential through their ability to ameliorate the side effects of conventional chemotherapy [14].

This study investigated the in vitro expression of cyclin B1 and Cdc2 in PA-1 cells. The cells possess mechanisms to maintain genomic stability through cell cycle arrest [15]. At least two cell cycle checkpoints play a role in the cellular response, allowing the DNA to be repaired prior to DNA duplication (G1/S checkpoint) or mitosis (G2/M checkpoint) [16]. Cdc2 regulates mitosis and binds to cyclin B to form mitosis-promoting factor (MPF) [17]. The activity of MPF is regulated by the phosphorylation/dephosphorylation of Cdc2 as well as the accumulation of cyclin B protein and p53; GADD45 is also involved in a G2/M checkpoint and may participate in the regulation of Cdc2 kinase activity $[18,19]$.

Other lines of evidence suggest that DNA damage excludes cyclin B1 from the nucleus, which promotes G2 arrest [20]. It is possible that cell cycle checkpoints delay cell cycle progression to allow additional time for the repair of DNA damage; however, our study found no direct evidence that DNA was repaired while the cells were arrested at the checkpoint.
Recent studies have shown that SFN inhibits the growth of tumor precursors and tumors in mice models when treatment is initiated at the time of carcinogen administration [10]. The co-inhibition of PI3K/AKT and ERK pathways activates FOXO transcription factor and enhances SFN-induced FOXO transcriptional activity, leading to cell cycle arrest and apoptosis [21].

\section{Conclusions}

We conclude that G2 delay is a common response of tumor cells to chemotherapy with SFN. We further propose that mechanisms of this delay may be reduced expression of $\mathrm{CDC} 2$ and dissociation of the cyclin B1/ CDC2 complex. Therefore, although certain chemopreventive effects of SFN and related isothiocyanate compounds have already been established with regard to ovarian cancer cells, SFN should be investigated further to confirm the additional antitumor properties proposed by our study.

\section{Competing interests}

The authors declare that they have no competing interests.

\section{Authors' contributions}

CCC participated in its design and coordination and drafted the manuscript. YRY carried out the FACS analysis, cell culture and carried out the molecular studies. CMH performed the statistical analysis. YCH conceived of the study, and participated in its design and coordination and helped to draft the manuscript. All authors read and approved the final manuscript.

\section{Acknowledgment}

The authors would like to express their appreciation for the funding support provided by the E-Da Hospital, E-Da Hospital/I-Shou University. (EDAHP-100018).

\section{Author details}

${ }^{1}$ Department of Obstetrics \& Gynecology, Tainan Sin-Lau Hospital, Tainan, Taiwan. Department of Obstetrics \& Gynecology, E-Da Hospital/I-Shou University, Kaohsiung, Taiwan. ${ }^{3}$ Department of General Surgery, E-Da Hospital, I-Shou University, Kaohsiung, Taiwan. ${ }^{4}$ Department of Bioscience Technology, College of Health Sciences, Chang Jung Christian University, Tainan, Taiwan. ${ }^{5}$ Graduate Institute of Medical Science, College of Health Sciences, Chang Jung Christian University, Tainan, Taiwan. ${ }^{6}$ Innovative Research Center of Medicine, College of Health Sciences, Chang Jung Christian University, Tainan, Taiwan.

Received: 18 April 2013 Accepted: 12 June 2013

Published: 26 June 2013

\section{References}

1. Singh SV, Singh K: Cancer chemoprevention with dietary isothiocyanates mature for clinical translational research. Carcinogenesis 2012, 33:1833-1842

2. Xu T, Ren D, Sun X, Yang G: Dual Roles of Sulforaphane in Cancer Treatment. Anticancer Agents Med Chem 2012, 12:1132-1142.

3. Huang TY, Chang WC, Wang MY, Yang YR, Hsu YC: Effect of sulforaphane on growth inhibition in human brain malignant glioma GBM 8401 cells by means of mitochondrial- and MEK/ERK-mediated apoptosis pathway. Cell Biochem Biophys 2012, 63:247-259.

4. Alp H, Aytekin I, Hatipoglu NK, Alp A, Ogun M: Effects of sulforophane and curcumin on oxidative stress created by acute malathion toxicity in rats. Eur Rev Med Pharmacol Sci 2012, 16:144-148.

5. Yanaka A, Sato J, Ohmori S: Sulforaphane protects small intestinal mucosa from aspirin/NSAID-induced injury by enhancing host defense systems against oxidative stress and by inhibiting mucosal invasion of anaerobic enterobacteria. Curr Pharm Des 2013, 19:157-162. 
6. Devi JR, Thangam EB: Mechanisms of anticancer activity of sulforaphane from Brassica oleracea in HEp-2 human epithelial carcinoma cell line. Asian Pac J Cancer Prev 2012, 13:2095-2100.

7. Lin LC, Yeh CT, Kuo CC, Lee CM, Yen GC, Wang LS, Wu CH, Yang WC, Wu AT: Sulforaphane potentiates the efficacy of imatinib against chronic leukemia cancer stem cells through enhanced abrogation of Wnt/ $\beta$ catenin function. J Agric Food Chem 2012, 60:7031-7039.

8. Wiczk A, Hofman D, Konopa G, Herman-Antosiewicz A: Sulforaphane, a cruciferous vegetable-derived isothiocyanate, inhibits protein synthesis in humanprostate cancer cells. Biochim Biophys Acta 1823, 2012:1295-1305.

9. Hussain A, Priyani A, Sadrieh L, Brahmbhatt K, Ahmed M, Sharma C: Concurrent sulforaphane and eugenol induces differential effects on human cervical cancer cells. Integr Cancer Ther 2012, 11:154-165.

10. Chen MJ, Tang WY, Hsu CW, Wu JF, Lin CW, Cheng YM, Hsu YC: Apoptosis induction in primary human colorectal cancer cell lines and retarded tumor growth in SCID mice by sulforaphane. Evid Based Complement Alternat Med 2012, 201(2):415231.

11. Kombairaju P, Ma J, Thimmulappa RK, Yan SG, Gabrielson E, Singh A, Biswal S: Prolonged sulforaphane treatment does not enhance tumorigenesis in oncogenic K-ras and xenograft mouse models of lung cancer. J Carcinog 2012, 11:8.

12. Biswas S, Hwang JW, Kirkham PA, Rahman I: Pharmacologial and dietary antioxidant therapies for chronic obstructive pulmonary disease. Curr Med Chem 2013, 20:1496-1530.

13. Clarke JD, Hsu A, Williams DE, Dashwood RH, Stevens JF, Yamamoto M, Ho E: Metabolism and tissue distribution of sulforaphane in Nrf2 knockout and wild-type mice. Pharm Res 2011, 28:3171-3179.

14. Weissenberger J, Priester M, Bernreuther C, Rakel S, Glatzel M, Seifert V Kögel D: Dietary curcumin attenuates glioma growth in a syngeneic mouse model by inhibition of the JAK1,2/STAT3 signaling pathway. Clin Cancer Res 2010, 16:5781-5795.

15. Xue Y, Ren H, Xiao W, Chu Z, Lee JJ, Mao L: Antitumor activity of AZ64 via G2/M arrest in non-small cell lung cancer. Int J Oncol 2012, 41:1798-1808.

16. Tang L, Gao Y, Yan F, Tang J: Evaluation of cyclin-dependent kinase-like 1 expression in breast cancer tissues and its regulation in cancer cell growth. Cancer Biother Radiopharm 2012, 27:392-398.

17. Zhang $X$, Jia $S$, Yang $S$, Yang $Y$, Yang $T$, Yang $Y$ : Arsenic trioxide induces G2/M arrest in hepatocellular carcinoma cells by increasing the tumor suppressor PTEN expression. J Cell Biochem 2012, 113:3528-3535.

18. Oliveras-Ferraros $C$, Fernández-Arroyo $S$, Vazquez-Martin A, Lozano-Sánchez J, Cufí S, Joven J, Micol V, Fernández-Gutiérrez A, Segura-Carretero A, Menendez JA: Crude phenolic extracts from extra virgin olive oil circumvent de novo breast cancer resistance to HER1/HER2-targeting drugs by inducing GADD45-sensed cellular stress, G2/M arrest and hyperacetylation of Histone H3. Int J Oncol 2011, 38:1533-1547.

19. Shih RS, Wong SH, Schoene NW, Zhang JJ, Lei KY: Enhanced Gadd45 expression and delayed G2/M progression are p53-dependent in zincsupplemented human bronchial epithelial cells. Exp Biol Med 2010, 235:932-940.

20. Drews-Elger K, Ortells MC, Rao A, López-Rodriguez C, Aramburu J: The transcription factor NFAT5 is required for cyclin expression and cell cycle progression in cells exposed to hypertonic stress. PLoS One 2009, 4:e5245.

21. Davis $R$, Singh KP, Kurzrock R, Shankar S: Sulforaphane inhibits angiogenesis through activation of FOXO transcription factors. Oncol Rep 2009, 22:1473-1478.

doi:10.1186/1757-2215-6-41

Cite this article as: Chang et al: Sulforaphane induced cell cycle arrest in the G2/M phase via the blockade of cyclin B1/CDC2 in human ovarian cancer cells. Journal of Ovarian Research 2013 6:41.

\section{Submit your next manuscript to BioMed Central and take full advantage of:}

- Convenient online submission

- Thorough peer review

- No space constraints or color figure charges

- Immediate publication on acceptance

- Inclusion in PubMed, CAS, Scopus and Google Scholar

- Research which is freely available for redistribution

Submit your manuscript at www.biomedcentral.com/submit
Ciomed Central 